\title{
Effect of sperm concentration on boar spermatozoa mitochondrial membrane potential and motility in semen stored at $17^{\circ} \mathrm{C}$
}

\author{
Anna Wysokińska
}

Siedlce University of Natural Sciences and Humanities, Institute of Animal Science and Fisheries, Siedlce, Poland

Received June 2, 2020

Accepted December 21, 2020

\begin{abstract}
The aim of the study was to assess the effect of sperm concentration in the ejaculate on the mitochondrial membrane potential and motility of Landrace boar spermatozoa during storage of diluted semen at $17^{\circ} \mathrm{C}$. The study was conducted on ejaculates collected from 10 boars aged 1.5-2 years. Based on sperm concentration measurements, two groups of boars were identified: Group 1 - boars providing ejaculates with a sperm concentration of at least $500 \times 10^{3} / \mathrm{mm}^{3}$ and Group 2 - boars providing ejaculates with a sperm concentration of less than $500 \times 10^{3} / \mathrm{mm}^{3}$. Four ejaculates were collected manually from each boar. Each ejaculate was diluted with Biosolvens Plus diluent, and insemination doses were prepared and stored at $17^{\circ} \mathrm{C}$. Mitochondrial membrane potential and motility of spermatozoa were evaluated at each insemination dose. The tests were carried out after 1, 24, 48, 96 and $168 \mathrm{~h}$ of storage. Based on the results, it was found that ejaculates with a sperm concentration $\geq 500 \times 10^{3} / \mathrm{mm}^{3}$ have a lower share of spermatozoa with high mitochondrial membrane potential than ejaculates with a sperm concentration below $500 \times 10^{3} / \mathrm{mm}^{3}$. A high correlation between the share of spermatozoa with a high mitochondrial membrane potential and motility of spermatozoa was demonstrated in the first $24 \mathrm{~h}$ and after $96 \mathrm{~h}$ of semen storage, which was confirmed by the calculated phenotypic correlation coefficients. Sperm cells in ejaculates with a higher sperm concentration are more sensitive to storage time than spermatozoa in ejaculates with a lower concentration.
\end{abstract}

Ejaculate, pigs, semen quality

Insemination of pigs plays an important role in the reproduction of this animal species. It is the most common method of breeding pigs in the world that allows increasing the genetic progress of the swine population. Boars used in insemination are usually characterized by good production-related predisposition, as well as high breeding value. High variability observed in the physical characteristics of ejaculates, which affects the economics of using a given individual is a fairly serious problem faced by sow insemination stations. The source of this variation can be the boar breed (Schulze et al. 2014; Yeste 2016; Wysokińska and Kondracki 2019), age (Banaszewska et al. 2015), and environmental factors (Zasiadczyk et al. 2015; Kowalewski et al. 2016). Individual variation is also important in reproduction. This variability affects the male's predisposition for insemination use as males provide semen with different physical characteristics of the ejaculate. The ejaculate volume, sperm concentration and sperm motility are determined immediately after collection. Based on these indices, the number of insemination doses that can be obtained from the ejaculate is determined, and this determines the economic efficiency of using the individual in insemination. Some studies have shown the effect of sperm concentration on head dimensions and sperm morphology (Kondracki et al. 2011; Kondracki et al. 2013). It is possible that sperm cell concentration may also affect the potential of the spermatozoon mitochondrial membrane. Maintenance of normal mitochondrial membrane potential is necessary for mitochondria to produce adenosine triphosphate (ATP) (Luo et al. 2013). Mitochondria are thought to be important organelles that can be used to assess semen quality. Due to the fact that mitochondria contain their own DNA and membrane potential, they are easy to study (Amaral and Ramalho-Santos 2010). Disorders present

Address for correspondence:

Siedlce University of Natural Sciences and Humanities

Prusa 14 Str, 08-110 Siedlce, Poland
Phone: +48256431388

E-mail: anna.wysokinska@uph.edu.pl

http://actavet.vfu.cz/ 
in the mitochondria of the spermatozoon insert may be the cause of reduced sperm motility and, consequently, lower egg cell fertilization efficiency.

Mainly semen diluted and stored in a liquid state at $17{ }^{\circ} \mathrm{C}$ is used in insemination of pigs. Because of cell membrane structure, boar spermatozoa are particularly sensitive to activities performed during laboratory treatment and storage conditions (Vyt et al. 2007; Lopez Rodriguez et al. 2012; Schulze et al. 2013) and sperm transport (Schulze et al. 2018). It was found that during storage of diluted boar semen, there are changes in the integrity of sperm cell membranes (Gączarzewicz et al. 2010; Wysokińska and Kondracki 2014; Wysokińska et al. 2015). Some studies have shown that mitochondria are organelles that are the most damaged during sperm preservation (Ball 2008; GonzalezFernandez et al. 2012).

The aim of this study was to assess the effect of sperm concentration in an ejaculate on the mitochondrial membrane potential and motility of Landrace boar spermatozoa during the storage of diluted semen at $17^{\circ} \mathrm{C}$.

\section{Materials and Methods}

Animals and semen collection

The study involved 10 insemination boars of the Polish Landrace breed. The studied boars were 1.5-2 years old. All boars were healthy, kept in individual pens of an area of $6.3 \mathrm{~m}^{2}$ on a concrete floor with thermal and humidity insulation. Boars were fed individually with a granulated complete mixture, normalized according to boar feeding standards. Boars were guaranteed constant access to drinking water supplied via nipple drinkers. The subjects were selected for the study based on the assessment of sperm concentration measurements in all ejaculates collected every 4-5 days by manual method. In addition to the concentration of spermatozoa in each ejaculate, the volume of the ejaculate, the percentage of spermatozoa showing progressive movement and the total number of spermatozoa were determined (Table 1). The concentration of spermatozoa was determined by the colorimetric method using an AccuRead photometer (IMV Technologies, L'Aigle, France). Based on sperm concentration measurements, two groups of boars were identified: Group 1 - boars providing ejaculates with a sperm concentration of at least $500 \times 10^{3} / \mathrm{mm}^{3}$ and Group 2 - boars providing ejaculates with a sperm concentration of less than $500 \times 10^{3} / \mathrm{mm}^{3}$ (Table 1). Four ejaculates were manually collected from each boar for testing. The ejaculate sperm were diluted in Biosolvens Plus (Biochefa, Sosnowiec, Poland) commercial extender so that there were $2.7 \times 10^{9}$ sperm in one insemination dose (plastic bags, $90 \mathrm{ml}$ ). After dilution, insemination doses were stored at room temperature for one hour. After this time, the first semen evaluation was carried out as described below. Subsequent assessments were carried out after 24, 48, 96 and $168 \mathrm{~h}$, using other insemination doses that were opened immediately prior to testing. The diluted semen were stored at $17^{\circ} \mathrm{C}$.

Table 1. Physical characteristics of boar ejaculates depending on the sperm concentration (mean \pm standard error of the mean).

\begin{tabular}{lcc}
\hline \multirow{2}{*}{ Item } & \multicolumn{2}{c}{ Group of boars } \\
\cline { 2 - 3 } & $1\left(\geq 500 \times 10^{3} / \mathrm{mm}^{3}\right)$ & $2\left(<500 \times 10^{3} / \mathrm{mm}^{3}\right)$ \\
\hline Number of boars & 5 & 5 \\
Semen volume $(\mathrm{ml})$ & $229.32^{\mathrm{a}} \pm 3.44$ & $407.44^{\mathrm{b}} \pm 6.86$ \\
Sperm concentration $\left(\times 10^{3} / \mathrm{mm}^{3}\right)$ & $634.34^{\mathrm{a}} \pm 6.80$ & $335.60^{\mathrm{b}} \pm 4.28$ \\
Sperm motility $(\%)$ & $74.83^{\mathrm{a}} \pm 0.30$ & $74.60^{\mathrm{a}} \pm 0.26$ \\
Number of spermatozoa in the ejaculate $\left(\times 10^{9}\right)$ & $106.41^{\mathrm{a}} \pm 1.57$ & $97.07^{\mathrm{b}} \pm 1.58$ \\
\hline
\end{tabular}

a,b - values in rows marked with different superscripts differ significantly at $P<0.05$

Semen evaluation

Assessment of mitochondrial activity

Assessment of sperm cell mitochondrial activity was performed using fluorochrome JC-1 (Molecular Probes, USA). JC-1 is a fluorochrome accumulating in mitochondria. Depending on the size of the mitochondrial membrane potential $(\Delta \Psi \mathrm{m}), \mathrm{JC}-1$ aggregates are formed (when $\Delta \psi \mathrm{m}>80-100 \mathrm{mV}$ ) or JC-1 monomers (when $\Delta \Psi \mathrm{m}<80-100 \mathrm{mV}$ ). One $\mathrm{ml}$ of solution $(5 \mathrm{ml}$ of JC-1 dissolved in dimethyl sulphoxide with $800 \mathrm{ml}$ of distilled water added) was added to $1 \mathrm{ml}$ of diluted semen $\left(1.2 \times 10^{6}\right.$ spermatozoa). The entirety was mixed and incubated for 
$2 \mathrm{~min}$ at room temperature. Then $200 \mu \mathrm{l}$ of JC-1 Staining Buffer $5 \times$ was added - mixed by inversion and incubated for $20 \mathrm{~min}$ at $37^{\circ} \mathrm{C}$ and $5 \% \mathrm{CO}_{2}$ humidity. After incubation, the semen was centrifuged at $600 \times \mathrm{g}$ for $3 \mathrm{~min}$ at $2-8{ }^{\circ} \mathrm{C}$, the supernatant was removed and the spermatozoa-containing pellet was placed on ice. The spermatozoa were rinsed with $1 \mathrm{ml}$ cold solution $(400 \mu \mathrm{JC}-1$ Staining Buffer $5 \times$ diluted with $1600 \mu \mathrm{l}$ distilled water $)$. The prepared samples were stored for a maximum of $30 \mathrm{~min}$ on ice. A drop of semen was collected from each sample and placed on a microscope slide. In each preparation, 200 spermatozoa were evaluated, specifying spermatozoa with a high mitochondrial membrane potential (with high $\triangle \Psi \mathrm{m}$ JC-1 aggregates) (sperm cells emitting orange fluorescence in the mid-piece region), with a medium mitochondrial membrane potential (with medium $\Delta \Psi \mathrm{m}$ aggregates JC-1) (orange-green fluorescent spermatozoa in the mid-piece region), and with a low mitochondrial membrane potential (with low $\Delta \Psi \mathrm{m}$ JC-1 aggregates) (green fluorescent sperm in the mid-piece region) (Plate II, Fig. 1). The evaluation of the sperm mitochondrial membrane potential was performed using a fluorescence microscope (Nikon Eclipse 50i, Tokyo, Japan).

\section{Assessment of sperm motility}

Motility of spermatozoa was determined using the microscopic method by placing a drop of semen $(5 \mu 1)$ on a microscope slide heated to $37^{\circ} \mathrm{C}$, covering it with a $22 \times 22 \mathrm{~mm}$ cover slide. The percentage of progressive spermatozoa was determined by microscopic examination using a Nikon Eclipse 50i light microscope (Tokyo, Japan) and a heating table $\left(37^{\circ} \mathrm{C}\right)$. At a $\times 400$ magnification, the percentage of spermatozoa showing normal movement in the total number of spermatozoa visible in the microscope's field of view was determined.

Experimental data were analyzed using the program STATISTICA 13.1 PL (StatSoft, Tulsa, USA). Data were analyzed by ANOVA. All results were expressed as mean \pm standard error of the mean (SEM). The significance of the differences between the groups was assessed using Tukey test at $P<0.05$. Phenotypic correlation indices between sperm motility and sperm mitochondrial membrane potential were established based on Sperman's rank correlation coefficients.

\section{Results}

The percentage of spermatozoa with a high mitochondrial membrane potential depending on sperm concentration and semen storage time is shown in Fig. 2. Based on this data, it was found that there are differences in the number of spermatozoa with active mitochondria depending on sperm concentration and semen storage time. Boar semen from Group 1 (with a sperm concentration $\geq 500 \times 10^{3} / \mathrm{mm}^{3}$ ) had a lower number of sperm cells with a high mitochondrial membrane potential at 1, 96 and $168 \mathrm{~h}$ storage than Group 2 boar semen $\left(<500 \times 10^{3} / \mathrm{mm}^{3}\right.$ sperm concentration $)$. After the first hour of diluted semen storage, the difference between the groups was small and amounted to $2 \%$. The largest difference in the number of spermatozoa with a high mitochondrial membrane potential between the examined groups was found at 96 and $168 \mathrm{~h}$ of semen storage $(P<0.05)$. A decrease in the number of spermatozoa with a high mitochondrial membrane potential was found with the semen storage time. The largest decrease in the number of spermatozoa with a high mitochondrial membrane potential was found in storage for $48 \mathrm{~h}$ in ejaculates with a sperm concentration $\geq 500 \times 10^{3} / \mathrm{mm}^{3}$. The largest decrease in the share of spermatozoa with a high mitochondrial membrane potential can be seen in Group 1, where the difference between 1 and $168 \mathrm{~h}$ of semen storage was over $26 \%$, while in Group 2 this difference was over $19 \%$.

The percentage of spermatozoa with a medium mitochondrial membrane potential depending on sperm concentration and semen storage time is shown in Fig. 3. In the first $48 \mathrm{~h}$ of semen storage, there was a lower proportion of spermatozoa with an average mitochondrial membrane potential found in the ejaculates of boars from Group 1 compared to the ejaculates of boars from Group 2. After $96 \mathrm{~h}$ of semen storage, the share of spermatozoa with a medium mitochondrial membrane potential was greater in the semen of Group 1 boars than in the semen of Group 2 boars. Significant differences were found only after $168 \mathrm{~h}$ of semen storage. There was a noticeable increase in the share of spermatozoa with a medium mitochondrial membrane potential in both groups, depending on the semen storage time. In boar ejaculates of Group 1, changes in the share of spermatozoa with a medium mitochondrial membrane potential were more dynamic and an increase of $19.66 \%$ was observed between 1 and $168 \mathrm{~h}$ of storage, with an increase of $13.77 \%$ in Group 2. 


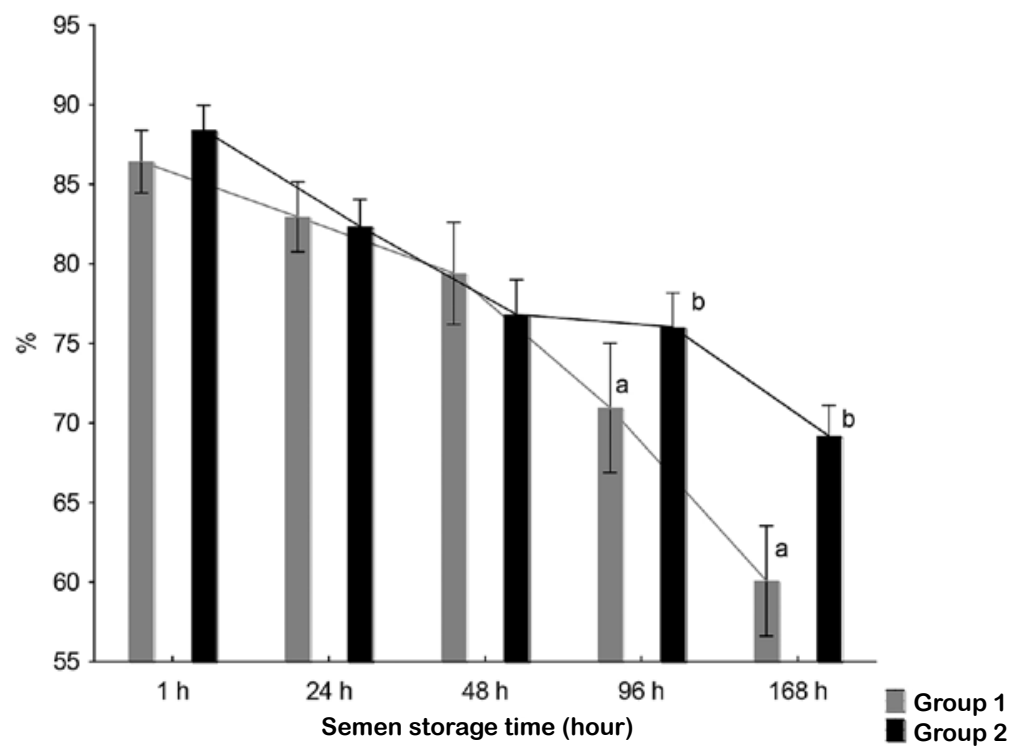

Fig. 2. Spermatozoa with a high mitochondrial membrane potential depending on the sperm concentration (Group 1 - sperm concentration $\geq 500 \times 10^{3} / \mathrm{mm}^{3}$; Group 2 - sperm concentration $<500 \times 10^{3} / \mathrm{mm}^{3}$ ) during the storage of diluted semen at $17^{\circ} \mathrm{C}$.

$\mathrm{a}, \mathrm{b}-P<0.05$. Bars represent means \pm standard error of the mean.

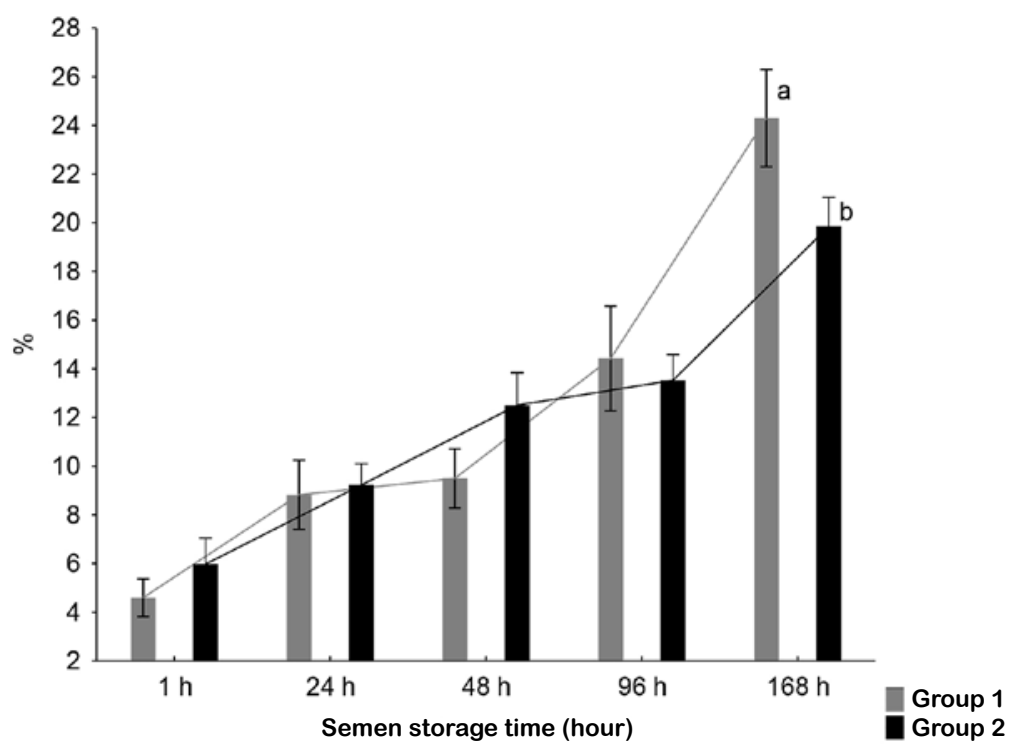

Fig. 3. Spermatozoa with a medium mitochondrial membrane potential depending on the sperm concentration (Group 1 - sperm concentration $\geq 500 \times 10^{3} / \mathrm{mm}^{3}$; Group $2-$ sperm concentration $<500 \times 10^{3} / \mathrm{mm}^{3}$ ) during the storage of diluted semen at $17^{\circ} \mathrm{C}$.

$\mathrm{a}, \mathrm{b}-P<0.05$. Bars represent means \pm standard error of the mean. 


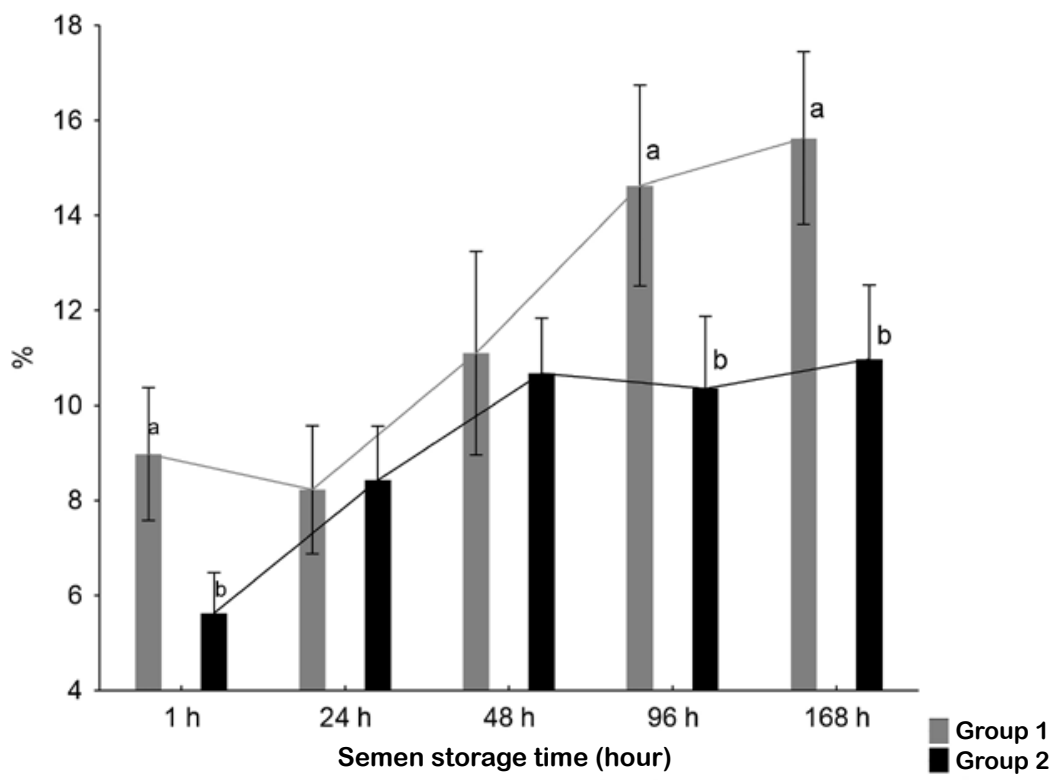

Fig. 4. Spermatozoa with a low mitochondrial membrane potential depending on the sperm concentration (Group 1 - sperm concentration $\geq 500 \times 10^{3} / \mathrm{mm}^{3}$; Group 2 - sperm concentration $<500 \times 10^{3} / \mathrm{mm}^{3}$ ) during the storage of diluted semen at $17^{\circ} \mathrm{C}$.

$\mathrm{a}, \mathrm{b}-P<0.05$. Bars represent means \pm standard error of the mean.

The results characterizing the percentage of spermatozoa with a low mitochondrial membrane potential depending on sperm concentration and semen storage time are shown in Fig. 4. In the group of boar ejaculates with a sperm concentration exceeding $500 \times 10^{3} / \mathrm{mm}^{3}$, a greater proportion of spermatozoa with a low mitochondrial membrane potential was observed compared to Group 2. The largest differences between the groups were found at 1,96 and $168 \mathrm{~h}$ of semen storage $(P<0.05)$. The data presented in Fig. 4 also show changes in the number of spermatozoa with a low mitochondrial membrane potential, depending on the duration of semen storage. Group 1 showed an approximately $7 \%$ increase in the number of spermatozoa with a low mitochondrial membrane potential from 24 to $168 \mathrm{~h}$ of semen storage. Slightly different tendencies of changes were observed in Group 2. From 48 to $168 \mathrm{~h}$ of semen storage, the share of spermatozoa with a low mitochondrial membrane potential remained at a similar level.

Table 2. Phenotypic correlation coefficients between the share of spermatozoa with a high mitochondrial membrane potential and the share of spermatozoa showing progressive motility.

\begin{tabular}{llllll}
\hline \multirow{2}{*}{$\begin{array}{l}\text { Motility } \\
\text { Mitochondrial membrane potential }\end{array}$} & \multicolumn{5}{c}{ Semen storage time } \\
\cline { 2 - 6 } & $1 \mathrm{~h}$ & $24 \mathrm{~h}$ & $48 \mathrm{~h}$ & $96 \mathrm{~h}$ & $168 \mathrm{~h}$ \\
\hline $1 \mathrm{~h}$ & $0.64^{*}$ & $0.60^{*}$ & $0.48^{*}$ & 0.29 & -0.10 \\
$24 \mathrm{~h}$ & $0.43^{*}$ & $0.51^{*}$ & $0.40^{*}$ & 0.14 & -0.11 \\
$48 \mathrm{~h}$ & -0.03 & 0.12 & 0.27 & 0.21 & $0.48^{*}$ \\
$96 \mathrm{~h}$ & 0.25 & 0.21 & $0.38^{*}$ & $0.62^{*}$ & $0.58^{*}$ \\
$168 \mathrm{~h}$ & 0.25 & 0.29 & $0.42^{*}$ & $0.56^{*}$ & $0.63^{*}$ \\
\hline
\end{tabular}

$* P<0.05$ 
Table 2 presents phenotypic correlation coefficients between the share of spermatozoa with a high mitochondrial membrane potential and the share of spermatozoa showing progressive movement at different times of semen storage. The presented data indicate that the phenotypic correlation coefficients between sperm cell motility and the share of spermatozoa with a high mitochondrial membrane potential are positive for most properties, high and demonstrate values between $0.38-0.64(P<0.05)$.

\section{Discussion}

The results of the present study indicate that the concentration of spermatozoa in the ejaculate affects the potential of the sperm cell mitochondrial membrane. Ejaculates with a sperm concentration $\geq 500 \times 10^{3} / \mathrm{mm}^{3}$ have a lower share of spermatozoa with a high mitochondrial membrane potential than ejaculates with a sperm concentration below $500 \times 10^{3} / \mathrm{mm}^{3}$. This is an important observation for the practice of insemination-related boar use. The concentration of spermatozoa determined in each collected ejaculate is, apart from the volume and motility of the spermatozoa, an indicator of the number of insemination doses that can be obtained from the ejaculate. The number of insemination doses determines the economic efficiency of boar use in insemination. Our study shows that ejaculates with a high sperm concentration are inferior in terms of mitochondrial activity in spermatozoa. Having considered the foregoing, it can be assumed that sperm cells from ejaculates with a high concentration of spermatozoa will be less effective in the process of egg cell fertilization. Some studies have shown a correlation between the morphometric dimensions of spermatozoa and their concentration in the ejaculate (Górski et al. 2018). Finding differences in the head dimensions of spermatozoa may be helpful in recognizing fertile subjects and those with reduced fertility (Gravance et al. 1996; Czubaszek et al. 2019).

Mainly semen stored at $15-17{ }^{\circ} \mathrm{C}$ is used in pig insemination. No detailed tests are carried out to assess the cellular structure of spermatozoa during semen storage, especially the activity of mitochondria located along the sperm insert. Sperm cell mitochondria are very active, they are subject to numerous metabolic processes present within them. These organelles are also involved in cell differentiation, reactive oxygen species (ROS) generation and apoptosis (Piomboni et al. 2012). There are many publications describing various changes occurring in mitochondria. However, the basic meaning of this sperm cell structure is based on providing ATP energy for sperm cell movement (Srivastava and Pande 2016). Mitochondrial membrane potential is the parameter that best reflects the mitochondrial function, and it is an indicator of the mitochondrial energy state. The potential of mitochondrial membrane is most often determined using fluorochromes. JC-1 is considered the most accurate indicator of mitochondrial membrane potential measurement, and it is able to detect minimal changes occurring in sperm cell mitochondria (Marchetti et al. 2004). Studies conducted mainly on human semen showed a relationship between limited mitochondrial function, demonstrated by reduced mitochondrial membrane potential, and reduced sperm motility and, consequently, reduced fertilization capacity (Paoli et al. 2011). In our study, a high correlation between the share of spermatozoa with a high mitochondrial membrane potential and motility of spermatozoa was observed in the first $24 \mathrm{~h}$ and after $96 \mathrm{~h}$ of semen storage, which is confirmed by the calculated phenotypic correlation coefficients (Table 2). Figueroa et al. (2013) showed a relationship between the mitochondrial membrane potential and the motility of conserved sperm cells. It is possible that there may be changes in the mitochondria of the sperm insert during storage of boar semen. The data presented in this paper clearly show that there are greater changes in the potential of the sperm cell mitochondrial membrane in semen with a higher sperm concentration compared to semen with a lower sperm concentration. 
In this study, it was found that spermatozoa from ejaculates with a lower sperm concentration (below $500 \times 10^{3} / \mathrm{mm}^{3}$ ) are less sensitive to semen storage conditions than spermatozoa from ejaculates with a sperm concentration $\geq 500 \times 10^{3} / \mathrm{mm}^{3}$. Along with the semen storage time, there is a more intense decrease in the number of spermatozoa with a high mitochondrial membrane potential in ejaculates with a sperm concentration $\geq 500 \times 10^{3} / \mathrm{mm}^{3}$ than in ejaculates with a sperm concentration below $500 \times 10^{3} / \mathrm{mm}^{3}$. The reduction in the percentage of spermatozoa with a high mitochondrial membrane potential observed in the present study, along with the extension of the semen storage time, may be associated with a change in plasma membrane permeability, which in turn may affect the mitochondrial membrane potential (Kumeresan et al. 2009). Studies on the assessment of sperm cell membrane integrity showed a decrease in the share of spermatozoa that retain normal structure of the cell membrane during semen storage (Wysokińska and Kondracki 2014). Other authors have also shown a deterioration in semen quality along with the extension of the storage time (Martín-Hidalgo et al. 2013; Wysokińska et al. 2015; Iljenkaite et al. 2020). In a study conducted by De Ambrogi et al. (2006), it was shown that sperm cell motility is significantly reduced after $72 \mathrm{~h}$ of storage.

A decrease in the percentage of spermatozoa showing progressive motion along with the time of semen storage was shown in this study. This decrease was more pronounced in ejaculates with a sperm cell concentration $\geq 500 \times 10^{3} / \mathrm{mm}^{3}$ than in ejaculates with a sperm cell concentration $<500 \times 10^{3} / \mathrm{mm}^{3}$.

In conclusion, it should be noted that the concentration of spermatozoa in the ejaculates of Landrace boars affects the potential of the mitochondrial membrane and sperm cell motility. Significantly fewer spermatozoa with a high mitochondrial membrane potential are observed in ejaculates with a higher sperm concentration than in ejaculates with a lower sperm concentration. Sperm from ejaculates with a higher concentration are more sensitive to the storage time, which is reflected in the intense decrease in the number of spermatozoa with a high mitochondrial membrane potential occurring with the increasing semen storage time. Sperm cells in ejaculates with a higher sperm concentration are more sensitive to the storage time than spermatozoa in ejaculates with a lower sperm concentration. Special supervision for the potential of the mitochondrial membrane should include ejaculates with a high sperm concentration.

\section{References}

Amaral A, Ramalho-Santos J 2010: Assessment of mitochondrial potential: implications for the correct monitoring of human sperm function. Int J Androl 33: 180-186

Ball BA 2008: Oxidative stress, osmotic stress and apoptosis: impacts on sperm function and preservation in the horse. Anim Reprod Sci 107: 257-267

Banaszewska D, Andraszek K, Biesiada-Drzazga B 2015: Evaluation of sperm chromatin structure in the semen of insemination boars. Bull Vet Inst Pulawy 59: 271-277

Czubaszek M, Andraszek K, Banaszewska D, Walczak-Jędrzejewska R 2019: The effect of the staining technique on morphological and morphometric parameters of boar sperm. PLoS One 14: 1-17

De Ambrogi M, Ballester J, Saravia F, Caballero I, Johannisson A, Wallgren M, Andersson M, RodriguezMartinez H 2006: Effect of storage in short and long-term commercial semen extenders on the motility, plasma membrane and chromatin integrity of boar spermatozoa. Int J Androl 29: 543-552

Figueroa E, Risopatrón J, Sánchez R, Isachenko E, Merino O,Valdebenito I 2013: Spermatozoa vitrification of sex-reversed rainbow trout (Oncorhynchus mykiss): Effect of seminal plasma on physiological parameters. Aquaculture 372-375: 119-126

Gączarzewicz D, Piasecka M, Udała J, Błaszczyk B, Stankiewicz T, Laszczyńska M 2010: Plasma membrane changes during the liquid storage of boar spermatozoa: a comparison of methods. Acta Vet Hung 58: 105-116

Gonzalez-Fernandez L, Morrell JM, Pena FJ, Macias-Garcia B 2012: Osmotic shock induces structural damage on equine spermatozoa plasmalemma and mitochondria. Theriogenology 78: 415-422

Górski K, Kondracki S, Wysokińska A, Iwanina M 2018: Dependence of sperm morphology and ejaculate characteristics on sperm concentration in the ejaculates of Hypor boars. J Vet Res 62: 353-357

Gravance CG, Liu IKM, Davis RO, Hughes JP, Casey PJ 1996: Quantification of normal head morphometry of stallion spermatozoa. J Reprod Fertil 108: 41-46 
Iljenkaite A, Kerziene S, Dauksiene A, Mikniene Z, Zilinskas H, Sutkeviciene N 2020: The effect of royal jelly on boar sperm viability and motility during liquid storage for 96 hours. Acta Vet Brno 89: 47-53

Kondracki S, Wysokińska A, Iwanina M, Banaszewska D, Sitarz D 2011: Effect of sperm concentration in an ejaculate on morphometric traits of spermatozoa in Duroc boars. Pol J Vet Sci 14: 35-40

Kondracki S, Banaszewska D, Bajena M, Komorowska K, Kowalewski D 2013: Correlation of frequency of spermatozoa morphological alterations with sperm concentration in ejaculates of Polish Landrace boars. Acta Vet Beograd 63: 513-524

Kowalewski D, Kondracki S, Górski K, Bajena M, Wysokińska A 2016: Effect of piggery microclimate on ejaculate performance of artificial insemination boars. Kafkas Univ Vet Fak Derg 22: 225-232

Kumaresan A, Kadirvel G, Bujarbaruah KM, Bardoloi RK, Das A, Kumar S, Naskar S 2009: Preservation of boar semen at $18^{\circ} \mathrm{C}$ induces lipid peroxidation and apoptosis like changes in spermatozoa. Anim Reprod Sci 110: 162-171

Lopez Rodriguez A, Rijsselaere T, Vyt P, Van Soom A, Maes D 2012: Effect of dilution temperature on boar semen quality. Reprod Dom Anim 47: 63-66

Luo S, Schatten H, Sun Q 2013: Sperm mitochondria in reproduction: good or bad and where do they go? J Genet Genomics 40: $549-556$

Marchetti C, Jouy N, Lerroy-Martin B, Defossez A, Formstecher P, Marchetti P 2004: Comparison of four fluorochromes for the detection of the inner mitochondrial membrane potential in human spermatozoa and their correlation with sperm motility. Hum Reprod 19: 2267-2276

Martín-Hidalgo D, Barón FJ, Robina A, Brygado MJ, Hurtado de Llera A, García-Marín LJ, Gil MC 2013: Interand intra-breed comparative study of sperm motility and viability in Iberian and Duroc boar semen during long-term storage in MR-A and XCell extenders. Anim Reprod Sci 139: 109-114

Paoli D, Gallo M, Rizzo F, Baldi E, Francavilla S, Lenzi A, Lombardo F, Gandini L 2011: Mitochondrial membrane potential profile and its correlation with increasing sperm motility. Fertil Steril 95: 2315-2319

Piomboni P, Focarelli R, Stendardi A, Ferramosca A, Zara V 2012: The role of mitochondria in energy production for human sperm motility. Int J Androl 35: 109-124

Schulze M, Bortfeldt R, Schäfer J, Jung M, Fuchs-Kittowski F 2018: Effect of vibration emission during shipping of artificial insemination doses on boar semen quality. Anim Reprod Sci 192: 328-334

Schulze M, Buder S, Rüdiger K, Beyerbach M, Waberski D 2014: Influences on semen traits used for selection of young AI boars. Anim Reprod Sci 148: 164-170

Schulze M, Henning H, Rudiger K, Wallner U, Waberski D 2013: Temperature management during semen processing: impact on boar sperm quality under laboratory and field conditions. Theriogenology 80: 990-998

Srivastava N, Pande M 2016: Mitochondrion: Features, functions and comparative analysis of specific probes in detecting sperm cell damages. Asian Pacific J Reprod 5: 445-452

Wysokińska A, Kondracki S 2014: Assessment of changes in sperm cell membrane integrity occurring during the storage of semen from genetically different males using two diagnostic methods. Can J Anim Sci 94: 601-606

Wysokińska A, Kondracki S 2019: Heterosis for morphometric characteristics of sperm cells from Duroc x Pietrain crossbred boars. Anim Reprod Sci 211: 106217

Wysokińska A, Kondracki S, Iwanina M 2015: The usefulness of selected physicochemical indices, cell membrane integrity and sperm chromatin structure in assessments of boar semen sensitivity. Asian-Australas J Anim Sci 28: $1713-1720$

Vyt P, Maes D, Sys SU, Rijsselaere T, Van Soom A 2007: Air contact influences the pH of extended porcine semen. Reprod Dom Anim 42: 218-220

Zasiadczyk L, Fraser L, Kordan W, Wasilewska K 2015: Individual and seasonal variations in the quality of fractionated boar ejaculates. Theriogenology 83: 1287-1303

Yeste M 2016: Sperm cryopreservation update: Cryodamage, markers, and factors affecting the sperm freezability in pigs. Theriogenology 85: 47-64 
Plate II

Wysokińska A.: Effect of sperm... pp. 333-340

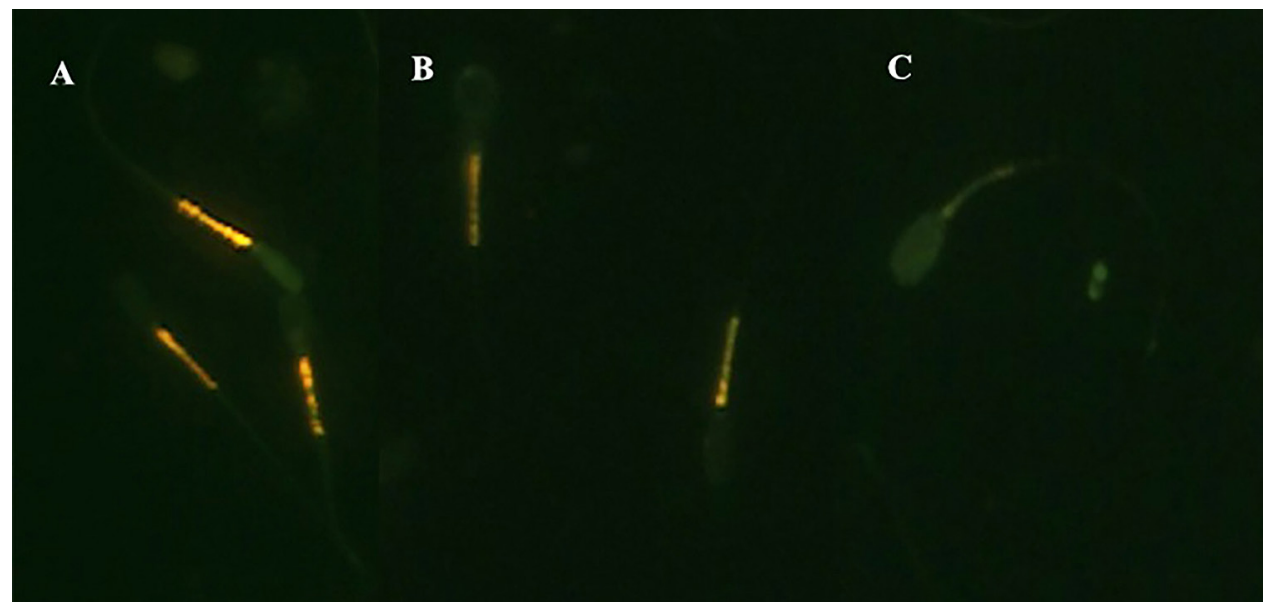

Fig. 1. Microscopic image of JC-1-stained boar spermatozoa: A - sperm cell with high $\Delta \Psi \mathrm{m}$ (orange fluorescence of the insert region); $\mathrm{B}$ - sperm cell with medium $\Delta \Psi \mathrm{m}$ (orange and green fluorescence of the insert region); $\mathrm{C}$ - sperm cell with low $\Delta \Psi \mathrm{m}$ (green fluorescence of the insert region) 